\title{
Population Ageing, Urbanization and Housing Demand
}

\author{
Zhangming Wang, Chengzhang Wang, Qian Zhang \\ School of Economics and Management, Southwest Jiaotong University, Chengdu, China \\ Email: 986727325@qq.com, wang-chengzhang@163.com, 756784334@qq.com
}

Received 2 July 2015; accepted 3 August 2015; published 6 August 2015

Copyright (C) 2015 by authors and Scientific Research Publishing Inc.

This work is licensed under the Creative Commons Attribution International License (CC BY). http://creativecommons.org/licenses/by/4.0/

c. (i) Open Access

\begin{abstract}
Using overlapping generation model, we find that population ageing does restrain housing demand. Then, we use the panel data of China's 31 provinces between 2002 and 2013 to confirm that ageing restrains housing demand, the process of urbanization does the opposite and maybe offsets the negative effect to some extent. At present, China should continue to focus on developing urbanization rapidly, especially focus on the population urbanization. In the process, the government should change its development ideas and increase the supply of public service for population ageing.
\end{abstract}

\section{Keywords}

Population Ageing, Population Urbanization Rate, Housing Prices

\section{Introduction}

In general, the main factors that affect the housing demand include the level of economic growth, urbanization, population age structure, per capita income level, etc. Population age structure is one of the important factors affecting housing prices. Housing-age population (25 to 49 years old) decline in the proportion and the proportion rise of elderly people lead to a decline in housing demand, while population ageing ${ }^{1}$ will bring an increase of housing supply, which will have a negative impact on prices.

Since the 20th century, with the extension of life expectancy and the decline of birth rate, the European and American developed countries have successively entered the stage of population ageing. Germany, Japan's housing-age population reached peak in 1995 and 1995 respectively, basically around 34\%; around 1995 in Germany, housing prices was in a gently rising stage, while the Japanese housing was rising after 1980. But

\footnotetext{
${ }^{1}$ Population ageing, internationally recognized definition refers to the population aged 60 and above is more than $10 \%$ of the total population or the population aged 65 and above is more than $7 \%$.
} 
these countries entered a stage of a population ageing and the overall prices growth was very slow. America experienced the "Baby Boom" period in the 1950s. The emergence of a short period of reproductive peak transformed into a housing demand in the 1980's, prompting the US overall prices rose more than 19\%, but the real estate price growth was very slow in the 90s. The micro questionnaire survey showed that the housing demand of people aged 20 to 50 was the highest and that the housing demand of elderly aged 60 and over was lower [1].

The demographic dividend characterized by "high labor population ratio" and "low dependency ratio", was the important reason for the rapid development of our country's economy over the past thirty years. China experienced baby boom in the 1950s to 1970s, and after the 70s began to implement a strict family planning policy and continued until now, resulting in the very short interval between children's dependency ratio declining period and the elderly dependency ratio rising period in our country and the rapid increase of the whole social endowment burden. The change meant that the demographic dividend of economic growth, namely an additional advantage of economic growth would gradually weaken and even disappear [2]. At present, China is the world's most populous country in the elderly, accounting for $20 \%$ of the world's elderly population. In 2000 , our country had a population of more than $10 \%$ of the total population over the age of 60 . The elderly people of 65 years old and above accounted for about $7 \%$. Our country formally entered the ageing society. Sixth national census in 2010 showed that the population of aged 60 and above accounted for $13.26 \%$ of the country's population and that aged 65 and above accounted for about $8.9 \%$. The sampled data also showed a trend of rapid rise. In 2013, the percentage of the population aged 65 or older has reached 9.7\% (as shown in Figure 1). In 2008, China's housing-age population reached a peak of about 470 million. After this, there was a sustained decline. Some scholars predicted that the impact on China's housing demand would fall sharply after 2012 [3].

However, unlike the developed countries, the urbanization rate of our country is still at a low level, lagging behind the economic development significantly. Japan's housing-age population is most in 1980. The urbanization rate has been close to $80 \%$; our country's housing-age population is most in 2008 , at the same time the urbanization rate only reaches close to $47 \%$ level. At present, our country is in the process of rapid urbanization. In 1999-2013, the average annual growth is 1.3 percentage points (as shown in Figure 2). This means that, as the rapid advance of urbanization in our country in the next 20 - 30 years, the population from rural areas to towns will still create a lot of housing demands.

The authors believe that although the Chinese population ageing level is increasing year by year and the demand for housing is undoubtedly a great negative impact, the rapid urbanization may offset the impact to some extent. Based on this, this paper plans to test the effects of two factors on China's housing market empirically, combines with the empirical results and experience of the abroad and puts forward the suggestion for the future development of China's housing market.

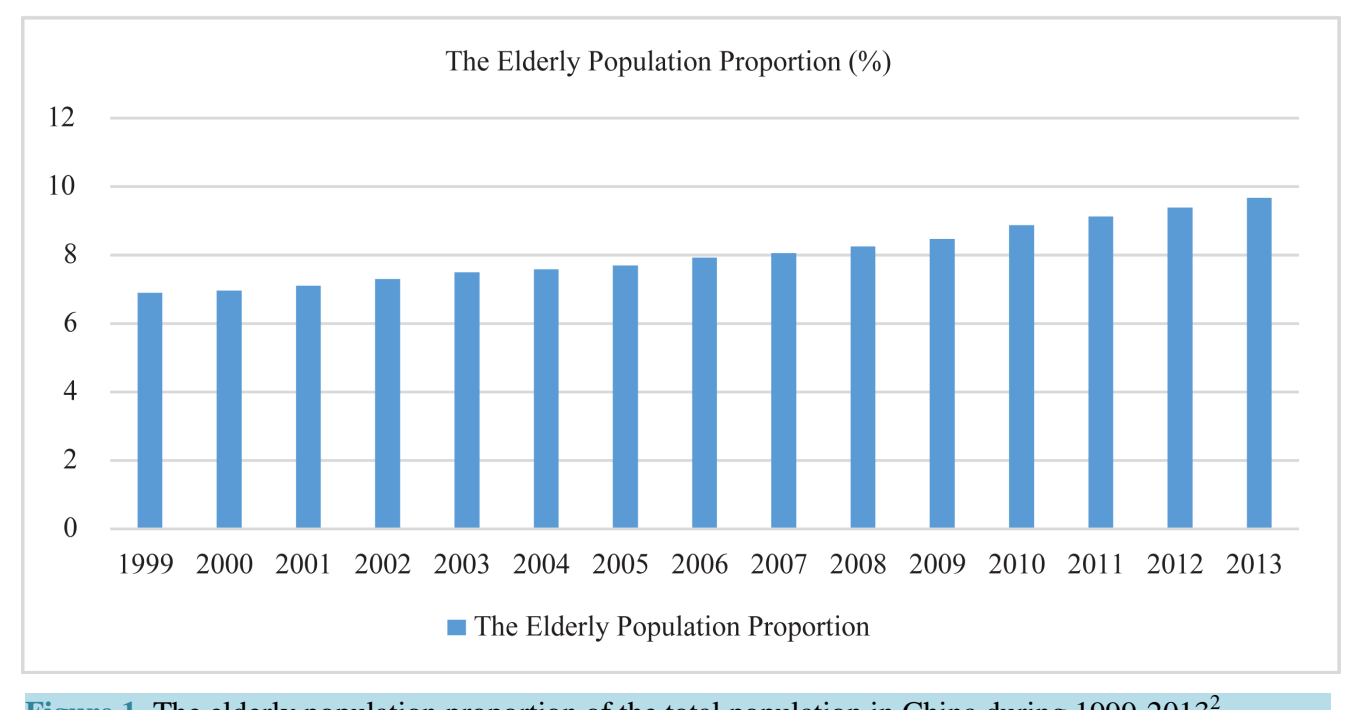

Figure 1. The elderly population proportion of the total population in China during 1999-2013².

\footnotetext{
${ }^{2}$ Data are from China Statistical Yearbook, the web site is http://www.stats.gov.cn/tjsj/ndsj/.
} 


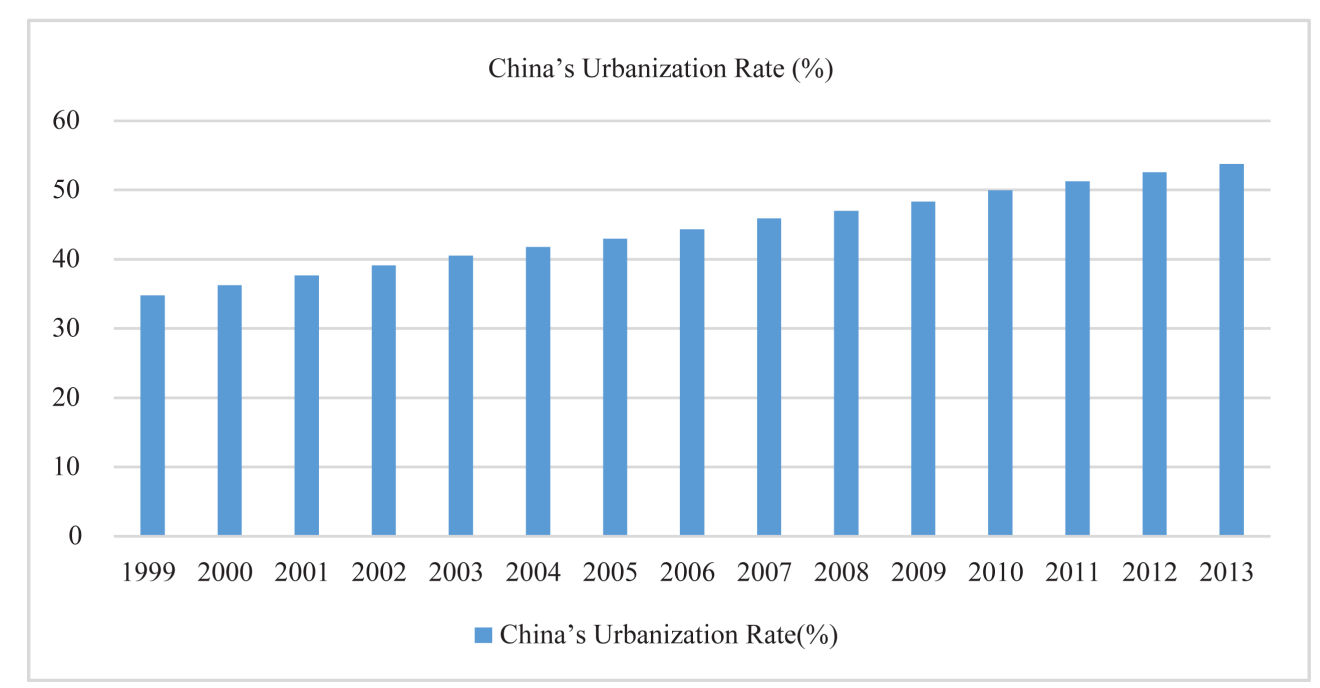

Figure 2. 1999-2013 China’s urbanization rate ${ }^{3}$.

\section{Literature Review}

Population ageing is the important problem of our country in recent years. Scholars have done a lot of research on it, but as a result of the census data are difficult to obtain, therefore there are few relevant empirical papers. Cai Fang in 2010 tested the demographic dividend gradually disappear and the arrival of lewis turning point judgment and China is faced with "old before getting rich" situation [4]. Hu Angang, et al. used so low model, from the theoretical and empirical aspects to verify the population ageing and population growth would have a negative impact on economic growth [5]. It is found that China's ageing population has the characteristics of the unbalanced spatial distribution and the expansion trend of regional differences. Per capita GDP and birth rate are the two most important factors affecting China's population ageing. The urbanization rate has a great positive impact on middle and western ageing [6].

The effect of population ageing on housing demand has been concerned by scholars at home and abroad. Population ageing significantly affected housing prices from the theoretical and empirical aspects [7]. Population factor was the long-term factor that economic development needed to focus on. Chen constructed overlapping generation model to investigate the influence of the change of population structure on prices, considered the declining of children dependency ratio be the demographic factors which caused the sustained rise in our country's housing price. Because the elderly exist altruistic motivation, the elderly dependency ratio rise is also the driving force for prices rising currently, but this power would weaken and reverse with the increase of the degree of ageing [8]. Li Xiang etc. used the macro data from 1995 to 2009 to investigate effects of China's population age structure on housing supply, housing consumption and housing prices. The study found: 50-64 crowd proportion and housing supply, consumption and prices were significantly positive correlation; at marriage age 15 - 29 crowd proportion was positively related to residential consumption and housing prices; aged 65 and over crowd proportion was negatively related to the housing supply [9]. Chen et al. with the international experience predicted that in short or medium term, population ageing would not lead to a large surplus of China's urban housing. Urbanization and family size miniaturization will boost China's urban housing demand continues to increase in the next 20 years to 30 years, which will make the negative impact of population ageingon the urban housing demand gradually emerge until 2045 [10]. Zhou Yu et al. analyzed the influence of population structure on housing prices in Beijing, found that population urbanization rate, including the transference of the third industrial employees, were likely to be important factors in the development of the real estate market in the next ten years. Demographic factors would have a negative impact on housing prices over a long period of time [11]. Zou Jin study showed that the population ageing played a role in promoting the rise of housing prices, but the trend could be reversed in the long-term, and there were some differences in the situation of different regions [12]. Xiao Zhi analyzed the effect of population age structure on residential segment prices, found that the

${ }^{3}$ Data is from China Statistical Yearbook, the web site is http://www.stats.gov.cn/tjsj/ndsj/. 
population dependency ratio and housing prices had significantly negative correlation, and had the greatest impact on ordinary commercial housing market prices, minimum impact on the villa market prices [13]. Xu Jianwei compared to OECD countries experience, found that although the increase of China's youth dependency ratio would bring housing prices rise and the effect of the elderly population dependency ratio increase was just the opposite, but he did not explain the reasons [14].

Urbanization was the focus of the scholars after the 18th party congress. It closely linked with real estate development. Chang Liang found that the level of urbanization has a positive impact on housing prices, and the level of urbanization has an increasing trend in the elasticity of housing prices, for this situation, should develop small and medium-sized cities in the regional differentiation of urbanization process [15]. Han Zhenglong studied the relationship among the regional differences, urbanization and housing prices. The empirical results showed that the urbanization effect on the real-estate prices was not significant. The reason was that the income differences in urban and rural areas caused the negative "quality" effect on the real-estate prices offsetting the positive "quantity" effect of urbanization. Put forward the urbanization development should gradually change to pay attention to quality from quantity [16]. Xue Fei empirically found urbanization and China's real estate have a closer correlation and the improvement of urbanization level has obvious impetus to the development of China's real estate [17]. Li Yongle discussed the influence mechanism of real estate price changes on land urbanization and found that the rise of real estate prices had a remarkable effect on the land urbanization at present. Inhibit the rapid rise of housing prices can effectively slow down the process of land urbanization [18]. Fan Jin et al. pointed out that although the urbanization construction in China had made great achievements. At present, China's land urbanization was clearly faster than the population urbanization. Dual land system, the dual household registration system and the investment oriented development strategy were the fundamental reason [19].

Reviewing the relevant literature, although domestic scholars have affirmed the fact that the population ageing inhibits the housing demand and some microscopic investigation have also obtained the relevant evidence, basically got the opposite conclusion from China's specific empirical data. The explanation given is China's traditional ideas make the elderly population buy a house for their children, the population ageing increases housing demand. Compared with the situation of developed countries, the level of urbanization in China is still at a low level, and the quality is not high, the above examples do not incorporate it into the framework of the research. Based on this, this paper hopes to study the effect of population ageing and population urbanization on the housing demand from theoretical and empirical perspectives to verify the above conjecture.

\section{Theoretical Model}

\subsection{Model Setting}

According to the study of Allais [20], Samuelson [21] and Diamond [22], the standard overlapping generation model, assuming an agent's lifetime is divided into two phases: a young age, and old age. When the agent is young and work and get income (assuming that the income is given), the income is used for consumption and savings. The old age will save all for consumption. Its savings include legal real estate, financial securities and other physical assets. The utility function $(U)$ of the agent can be expressed as:

$$
U=\ln \left(c_{t}^{Y}\right)+\beta \ln \left(c_{t+1}^{O}\right)
$$

Among them, $c^{Y}$ is the consumption of young age, $c^{O}$ is the consumption of old age, $\beta$ is the discount rate. The budget limiting condition of the agent maximizing its utility function is:

$$
c_{t}^{Y}+\frac{C_{t+1}^{O}}{1+r_{t}} \leq y_{t}^{Y}
$$

That is, the discount value of the consumption of the young age $c^{Y}$ and the consumption of the old age $c^{O}$ should be less than or equal to the income of the young age $y^{Y}$. Interest rates $r_{t}$ are inside the model, used to measure changes in asset prices. The agent's single sale, dispersive and other legitimate assets $K$, the price of the $t$ period is $p_{t}$. Young agents purchase $a_{t}$ shares of assets with unit price $p_{t}$. Therefore, budget constraints can be rewritten as follows:

$$
y_{t}^{Y}=c_{t}^{Y}+p_{t} a_{t}
$$


Because the agent has a general representative, when equilibrium, the total income is equal to the total consumption, so the assets of a single young agent are equal to total assets price $p_{t} K$ divided by the number of the current young agents $n_{t}^{Y}$, so type (3) can be rewritten as:

$$
y_{t}^{Y}=c_{t}^{Y}+p_{t}\left(\frac{K}{n_{t}^{Y}}\right)
$$

So in the period of $t+1$, old age agents will sell the assets of savings in price $p_{t+1}$ for consumption, is as follows:

$$
c_{t+1}^{O}=p_{t+1}\left(\frac{K}{n_{t}^{Y}}\right)=\frac{p_{t+1}}{p_{t}}\left(\frac{p_{t} K}{n_{t}^{Y}}\right)=\left(1+r_{t}\right)\left(\frac{p_{t} K}{n_{t}^{Y}}\right)
$$

Type (5) shows, the consumption of the agent in the old age is determined by the initial savings $\left(p_{t} K / n_{t}^{Y}\right)$ and the income of the interest $\left(1+r_{t}\right)$.

Because this paper needs to discuss the effects of population age structure on housing prices, two new variables should be introduced, $d_{t}$ is the proportion of the number of young people and the number of the elderly in the $t$ period, $g_{t}$ is exogenous given income growth rate. Formula is as follows:

$$
\begin{aligned}
& n_{t+1}^{Y}=\left(1+d_{t}\right) n_{t}^{Y} \\
& y_{t+1}^{Y}=\left(1+g_{t}\right) y_{t}^{Y}
\end{aligned}
$$

Standard transversality condition requires the overlapping generation model must satisfy:

$$
\forall t: \frac{p_{t} K}{n_{t}^{Y}} \leq y_{t}
$$

\subsection{Model Solution}

Type (1) belongs to the dynamic optimization problem. The first order necessary condition is:

$$
c_{t+1}^{O}=\beta\left(1+r_{t}\right) c_{t}^{Y}
$$

Combined with budget constraint conditions (2), the consumption of young age can be expressed as:

$$
c_{t}^{Y}=\frac{y_{t}^{Y}}{1+\beta}
$$

Vertical (4) and (10), get the equilibrium equations of individual savings equal investment:

$$
y_{t}^{Y}\left(1-\frac{1}{1+\beta}\right)=\frac{p_{t} K}{n_{t}^{Y}}
$$

The equilibrium equations of $t+1$ period can be expressed as

$$
y_{t}^{Y}\left(1+g_{t}\right)\left(1-\frac{1}{1+\beta}\right)=\frac{p_{t+1} K}{\left(1+d_{t}\right) n_{t}^{Y}}
$$

type (11) divided by type (12), can get the expression of return on assets

$$
1+r_{t+1}=\frac{p_{t+1}}{p_{t}}=\left(1+g_{t}\right)\left(1+d_{t}\right)
$$

As can be seen from the type (13), the number of the next generation of labor income and population increase, will improve the level of asset prices, because the workforce demand for assets will increase. Back stepping, if labor population declines, while the elderly population proportion rises, this will have a negative impact on asset prices.

\subsection{Establish Panel Data Measurement Model}

The above theoretical model can be deduced that the economic growth rate as well as the population factor de- 
cides housing prices in long term. The model has many simplified economic assumptions, for example, the number of housing supply is fixed and the agent will sell its property in his life cycle. In view of this, it needs to carry on a empirical research combined with the data of China. The economic growth factor of the type (13) can use the rate of per capita disposable income as a proxy variable and the demographic factor can be described by two factors, that is the core variable of the study: Elderly population dependency ratio (OLDDEP $)$ and population urbanization rate $\left(\operatorname{Urban}_{t}\right)$. In particular,

$$
O L D D E P_{t}=\frac{n_{t-1}}{n_{t}}=\frac{n_{t-1}}{n_{t-1}\left(1+d_{t-1}\right)}=\frac{1}{1+d_{t-1}}
$$

So we can get $\frac{\partial P_{t}}{\partial O L D D E P_{t}}<0$.

And the process of rapid urbanization, make a lot of the rural population move to cities. The housing demand from the two generations of rural population move to cities will partly offset the negative impact of population ageing. It can be considered that population urbanization will increase the housing-age population in cities and towns, thus promote housing demand, so presumably $\frac{\partial P_{t}}{\partial \text { Urban }_{t}}>0$.

Based on this, combining with the annual data of 31 provinces and cities, establishing panel data model, the model is as follows:

$$
\ln \left(P_{i t}\right)=\alpha_{i t}+\beta_{1} O L D D E P_{i t}+\beta_{2} \text { Urban }_{i t}+\beta_{3} \ln \left(P C D I_{i t}\right)+\sum \beta_{j} \text { Control vairables }_{i t}+\varepsilon_{i t}
$$

The selection of control variables is based on the study of the scholar before. The general can be divided into three categories: population size, demand factors and supply factors. See Table 1.

\section{Empirical Analysis}

\subsection{Data Acquisition and Processing}

This paper selects the annual data of 31 provinces in 2002-2013. They are from the National Bureau of Statistics website. The elderly population dependency ratio refers to the proportion of population aged 65 or over account for working population (15 - 64). Population urbanization rate shares the total population as a proxy variable.

To eliminate the influence of price factors, cities and provinces $P C D I_{i t}, S D P C_{i t}$, HCost $_{i t}$, Lprice $_{i t}$, Linv $_{i t}$ price adjustment take the year of 2000 as the base period. After the processing, is to take logarithm, but leave $O L D D E P_{i t}, U_{r b a n}$ it $U_{n e m p}$, CPI $I_{i t}$ alone.

\subsection{Panel Unit Root Test}

To avoid spurious regression, need to panel unit root test $\ln \left(P_{i t}\right), O L D D E P_{i t}, \operatorname{Urban}_{i t}$. To prevent the use of three methods Levin-Lin-Chu (LLC), Fisher, Im-Pesaran-Shin (IPS), the results are shown in Table 2. If there is no unit root, panel data can be directly panel data regression.

\begin{tabular}{cc} 
Table 1. List of control variables. & \\
\hline The Variable Name & Variable Symbol \\
\hline Population & Pop $_{i t}$ \\
Per Capita Deposit & SDPC $_{i t}$ \\
Unemployment Rate & Unemp $_{i t}$ \\
Consumer Price Index & CPI $_{i t}$ \\
Housing Cost & CCost $_{i t}$ \\
Land Price & Lprice $_{i t}$ \\
Land Investment & Linv $_{i t}$ \\
\hline
\end{tabular}


Table 2. Results of panel unit root test.

\begin{tabular}{cccc}
\hline Variable & LLC & Fisher & IPS \\
\hline $\ln \left(P_{i t}\right)$ & $-8.818\left(0.000^{* * *}\right)$ & $186.452\left(0.000^{* * *}\right)$ & $-2.447\left(0.007^{* * *}\right)$ \\
OLDDEP & $-7.904\left(0.000^{* * *}\right)$ & $198.282\left(0.000^{* * *}\right)$ & $-5.199\left(0.000^{* * *}\right)$ \\
Urban $_{i t}$ & $-6.599\left(0.000^{* * *}\right)$ & $119.220\left(0.000^{* * *}\right)$ & $-4.164\left(0.000^{* * *}\right)$ \\
\hline
\end{tabular}

Notes: The null hypotheses of three methods are panel data contain unit root; ${ }^{*},{ }^{* *},{ }^{* * *}$, is respectively at the $10 \%, 5 \%$ and $1 \%$ significance level.

\subsection{Panel Model Regression Results}

Hausman test of the model data shows that should accept the null hypothesis and consider that model should use random effect model, rather than a fixed effect model.

The fitting results of the model are good and the coefficients are very significant. See in Table 3.

As the table shows, the elderly population dependency ratio coefficient is significantly negative, urbanization rate coefficient is significantly positive, which are consistent with the above conjecture. It is indicated that the population ageing does have a negative impact on the housing market in China. Population coefficient is significantly negative which indicate that house price should decline as population increases. Per capita deposit and per capita disposable Income coefficients are both significantly positive which indicates the fact that house price always goes up as people' income increases. Housing cost and land price coefficients are both significantly positive, which indicates that the cost of house supply will increase the sale price. Unemployment rate and land investment coefficients are not significant.

\subsection{Result Analysis}

As the results show, the declining in housing demand and the increasing in housing supply of our country are similar to other countries in the world that are facing the problem of population ageing. Population ageing and urbanization are two extremely important components of demographic structure. Population ageing is a common phenomenon as the economy increases. It will have a negative effect on house market. Firstly, when most people are elderly, they usually own more than one house estate, so the intension to buy more estates is weak, which will decrease the house demand. Secondly, the house estates of elderly people will get back into trade market, which will increase the house supply. So population ageing will gradually decrease the house price. Many researches explain this effect. Developed countries' house markets are declining. The fact that population ageing inhibits housing demand and then affects the housing market negatively should be confirmed. But in China, the correlation between them is positive although China is getting "older". So many scholars have made conclusions that the elderly people exist "altruistic factor" to promote the housing development. However, according to the analysis of this paper, this may be that the scholars ignore the fact that China is experiencing the process of rapid urbanization, missing important explanatory variables. The core of urbanization is that rural population move to cities rapidly. Because of this, both the elderly population and working-age population have a strong demand for housing. This is an important thrust force for the housing market in China. The data of Figure 1 and Figure 2 show that the elderly population dependency ratio in our country is at an average annual growth of $0.21 \%$, the urbanization rate of $1.35 \%$. Assuming that other conditions unchanged, according to the coefficient of the model estimates: the increased housing demand in rapid urbanization is 1.7 times the reduced demand by population ageing. This can be considered one of the important demographic factors in rising housing prices in the past ten years. According to statistics, in 2005, China's new urban labor population reached 20 million peak, then gradually decreased, but by 2030, the new incremental still can reach about 3 million. If the annual rate of urbanization increased by $0.8 \%$ in the future, from 2015 to 2027, the annual urban housing-age population is at the levels of 245 million or so. This means, the next 15 - 20 years, the housing demand will continue to maintain the overall exuberant state. Housing demand caused by population urbanization can compensate the gap of the population ageing, and may even bring greater development opportunities. The regression coefficient of the control variables in Table 3 shows that the population size, per capita disposable income and other demand factors have a positive effect on the housing price, in which the growth of per capita disposable income has significantly positive impact on housing prices, the residents' purchasing power is the most important demand factor in deciding housing prices in the long-term; Consumer price index can reduce the purchasing 
Table 3. Regression results of panel random effect model.

\begin{tabular}{lcc}
\hline Variable & Coefficient & P values \\
\hline Elderly Population Dependency Ratio & -1.069 & $0.027^{* * *}$ \\
Urbanization Rate & 0.268 & $0.006^{* * *}$ \\
Population & -0.058 & $0.055^{* *}$ \\
Per Capita Deposit & 0.155 & $0.002^{* * *}$ \\
Per Capita Disposable Income & 0.827 & $0.000^{* * *}$ \\
Unemployment Rate & 0.008 & 0.630 \\
Consumer Price Index & -0.008 & $0.000^{* * *}$ \\
Housing Cost & 0.209 & $0.000^{* * *}$ \\
Land Price & 0.060 & $0.000^{* * *}$ \\
Land Investment & 0.027 & 0.185 \\
Intercept Item & -2.594 & $0.000^{* * *}$ \\
R Party & 0.914 & \\
\hline Notes: ${ }^{* * *},{ }^{* * *}$, is respectively at the $10 \%, 5 \%$ and $1 \%$ significance level. &
\end{tabular}

power of people in order to suppress the housing demand, and has a significantly negative effect on housing prices. On the supply side, housing prices, land prices pushed up the cost of housing, which has a positive effect on housing prices. However, unemployment rate, land investment has no significant impact on the housing prices.

\section{Conclusions and Suggestions}

This paper reviews the related literature both at home and abroad, although previous scholars have proved that population ageing has a negative effect on the housing demand from the theoretical model. Some scholars get the opposite conclusion from the empirical test of provincial data, so it gets some empirical explanation of the relatively strong demand that the elderly help children and older people buy a house to improve housing. Through the comparison, the authors find that the developed economies such as the United States, Japan and the EU are now facing the severe the population ageing and the lack of housing demand growth, but the obvious difference between the between China and them: the level of per capita income and urbanization of China are still at a low level. In terms of demographic factors, the rapid urbanization of China can stimulate the huge housing demand, which will largely offset the negative effect brought by the population ageing. Based on such speculation, this paper introduces the standard overlapping generation model and carries out the mathematical deduction of asset prices. Demonstration in theory: elderly population dependency ratio affects the housing prices negatively; the rate of urbanization affects the housing prices positively. Then, using the panel data of 31 provinces in 2002-2013, we prove the conjecture. Population ageing indeed suppresses housing demand, but at present the process of rapid urbanization in our country makes up for the part of the loss to some extent, which for the future development of housing market in China is of great significance.

a) Cities real estate development should adapt to the characteristics of the new urbanization, focus on the development of small towns. It not only can reduce big cities "congestion cost”, but also can meet more people's housing demand and reduce the costs of living; the core of urbanization is urbanization of population. The government should focus on the actual improvement of people's lives, pay attention to the construction of infrastructure and livelihood projects and not blindly emphasize land urbanization. The government needs to consider from the angle of financial sustainable development, control the speed and pace of urbanization effectively, not only pay attention to "quantity" and pay more attention to "quality".

b) Facing the fact of population ageing, cities in real estate development must change development ideas. The government can offer some preferential policies for the development of endowment property, guide the social capital to flow to the pension business, use market forces to meet a part of the pension demands, improve the quality of life of the elderly population and increase a new business type for enterprises simultaneously. At the 
same time, the government must strengthen the construction of elderly community public service, including medical services, convenient transportation and culture services, etc.

c) The demographic dividend gradually disappears, which has become an established fact that requires China need to transform development strategy, looking for new economic growth point, adhere to the reform and development. The ultimate goal is to increase people's disposable income, urban and rural integration development, narrow the income gap between urban and rural residents and provide high-quality public services. Population factors such as age structure and urbanization rate have a profound effect on China's economic and social development. We must learn from the development experience of all countries, explore the development pattern of its own characteristics, dealing with the development problem of "no rich first old" in China with a systematic way. Finally, I hope this paper can provide some theoretical and practical value for this problem.

\section{Acknowledgements}

This paper is supported by National Natural Science Foundation of China (NSFC) "The application research on micro econometric analysis and measurement of China's housing consumption and investment demand "(No. 71171169).

\section{References}

[1] Mankiw, N.G. and Weil, D.N. (1990) The Baby Boom, The Baby Bust, and the Housing Market. Regional Science and Urban Economics, 19, 235-258.

[2] Cai, F. (2004) Demographic Transition, Population Dividend, and Sustainability of Economic Growth. Population Research, 2, 2-9.

[3] Chen, B.K., Xu, F. and Tan, L. (2012) Demographic Transition and Housing Demand in China: Micro Empirical Research on Census Data from 1999 to 2025. Journal of Financial Research, 1, 129-140.

[4] Cai, F. (2010) Demographic Transition, Demographic Dividend, and Lewis Turning Point in China. Economic Research Journal, 4, 4-13.

[5] Hu, A.G., Liu, S.L. and Ma, Z.G. (2012) Population Ageing, Population Growth and Economic Growth: Evidence from Provincial Panel Data in China. Population Research, 3, 14-26.

[6] Chen, M.H. and Hao, G.C. (2014) Research on Regional Difference Decomposition and Influence Factors of Population Ageing in China. China Population, 4, 136-141.

[7] Takats, E., et al. (2012) Ageing and House Prices. Journal of Housing Economics, 21, 131-141. http://dx.doi.org/10.1016/j.jhe.2012.04.001

[8] Chen, G.J., Li, W. and Zhou, J. (2013) Research on the Relationship Between Population Structure and Housing Prices-An Analysis Based on Overlapping Generation Model and Provincial Panel Data in China. Economist, 10, 40-47.

[9] Li, X. and Gao, B. (2011) The Effect of Population Age Structure on Housing Market. Reform of Economic System, 6 , 38-42.

[10] Chen, Y.B. and Chen, X.L. (2013) The Influence of Population Ageing on China's Urban Housing Demand. Economic Theory and Business Management, 5, 45-58.

[11] Zhou, Y. and Cheng F. (2013) The Effect of Population Structure on Housing Prices-Based on Empirical Analysis of Beijing. Reformation \& Strategy, 11, 78-81.

[12] Zou, J. (2014) Demographic Trends and House Price Fluctuation-Evidence from China. Finance \& Economics, 6, $115-124$

[13] Xiao, Z. and Xu, Q. (2013) The Effect of Demographic Changes on Residential Segment Market—Based on Empirical Analysis of Panel Data. Modern Management Science, 12, 26-29.

[14] Xu, J.W., Xu, Q.Y. and H, F. (2012) Demographic Factors Behind the Rise in Housing Prices: International Experience and Evidence in China. The Journal of World Economy, 1, 24-42.

[15] Chang, L. and Jia, J.R. (2012) An Impact Study on the Relationship between Housing Price and Urbanization. Economic Survey, 3, 50-54.

[16] Han, Z.L. and Wang H.W. (2014) Regional Differences, Urbanization and Real Estate Prices—Evidence from China’s Real Estate Market. Inquiry into Economic Issues, 2, 63-70.

[17] Xue, F. and Yuan, R.H. (2014) Empirical Analysis on Urbanization Impact on the Development of Real Estate in China. Economic Geography, 4, 78-83. 
[18] Li, Y.L., Liu, J.S., Wu, Q. and Shu, B.R. (2014) Study on the Impact of Different Types of Housing Prices on Urbanization: Evidence from Provincial Panel Data in China. China Land Sciences, 4, 26-32.

[19] Fan, J. and Zhao, D.T. (2012) The Coordination Determination of Land Urbanization and Population Urbanization and Its Influencing Factors. Economist, 5, 61-67.

[20] Allais, M. (1947) Economieetinteret. Impremiere Nationale, Paris.

[21] Samuelson, P.A. (1958) An Exact Consumption-Loan Model of Interest with or without the Social Contrivance of Money. Journal of Political Economy, 66, 467-482. http://dx.doi.org/10.1086/258100

[22] Diamond, P. (1965) National Debt in a Neoclassical Growth Model. American Economic Review, 41, 1126-1150. 